\title{
MUSEOLOGÍA Y ANTROPOLOGÍA EN CASTILLA Y LEÓN: LOS SANTOS INOCENTES
}

\section{Luis Grau Lobo}

Museo de León

\section{Resumen.}

En una región caracterizada por su extensión, despoblación yanemia económica, el recurso a la etnografía como seña identitaria de la acción museística, especialmente a nivel local, ha generado varias oleadas de centros, apoyados o instados por las administraciones, y ha derivado en un panorama tanto más nutrido como uniforme, en el que se echan en falta perspectivas renovadoras, divergentes, y una planificación a escala territorial.

Palabras clave.

Museos locales, etnografía y etnología, identidad, tradición, Castilla y León.

\section{MUSEOLOGY AND ANTHROPOLOGY IN CASTILLA Y LEÓN: THE HOLY} INNOCENTS

\begin{abstract}
.
In a region characterized by its area, depopulation and economic anaemia, resorting to ethnography as the hallmark of the museum action, particularly at a local level, has
\end{abstract}


generated a surge of centers supported or promoted by the administration and have resulted in an abundant but uniform scene, in which reformist perspectives and territorial scale planning are lacking.

\section{Keywords.}

Local museums, ethnography and ethnology, identity, tradition, Castile and León

\section{ENTRADILLA A PROPÓSITO DE MUSEOS Y TERRITORIOS ${ }^{1}$}

El concepto de territorio es un invento moderno. Más allá del paisaje, entendido como espacio de estirpe pictórica o escenográfica en las artes y la cultura prerrománticas; o más allá de la naturaleza del Romanticismo, presta a otorgar un sentido espiritual y anímico a cuantas emociones individuales y colectivas le reclamaba su intérprete; sobrepasado el esenciero nacional - ¿identitario?- que los intelectuales de la Institución Libre de Enseñanza en España le otorgaron para dar pábulo a aquellas marcas de la casa que fueron el noventayochismo y la generación del 27, fecundos apologetas de perspectivas míticas y tópicas; el territorio se manifiesta como un logro de las ciencias que confluyen en la geografía humana, sin renunciar, en ocasiones, a las veleidades de aquellos caracteres nacionales. Hoy día, gracias a (o por culpa de) los modernos medios destinados a su comprensión y divulgación -los Google Earth y compañía-, el paisaje y el territorio han cambiado porque ha cambiado nuestra percepción de ellos, difundida universalmente a los cuatro vientos, al alcance de un clic.

Así, el territorio aglutina, en fértil amalgama de interrelaciones, lo físico, lo socioeconómico, lo medioambiental y lo cultural -entre otros- para conformar un sistema de cierta y relativa autonomía cuyo reconocimiento depende de la óptica y el observador que se empleen. $Y$ es aquí donde cabe esperar o puede esperarse que juegue un papel de atalaya, de lente oftalmológica, el museo. $\mathrm{O}$, cuando menos, la museología, erigida en una forma de mirar y comprender ese escenario y a sus agentes. Para tal intento, se entrelazan en el museo patrimonios con muy distintos apellidos. Uno de ellos, el etnográfico (etnológico, antropológico: nótese la incertidumbre de las etiquetas), tipología de precaria concreción, suele sumirse precisamente en ese concepto extenso, casi ubicuo: el del territorio, desembocadura de las ansias omnívoras del Museo, y suprema derivación de su pecado original, la búsqueda de la contextualización.

Porque, si ya era difícil lograr una correcta musealización (o museización) del bien arqueológico o el artístico, amputados de un contexto idealizado y pretérito que, en

1. El texto y los capítulos del mismo se enriquecen con títulos de obras de Miguel Delibes. Sirvan de homenaje. 
muchas ocasiones, tan sólo se le supone y siempre se ha perdido irremisiblemente, ¿cómo comportarse respecto a un bien cultural cuya trama originaria nos es tan conocida y cercana, tan real, y que, sin embargo, exige como primera renuncia, casi conditio sine qua non para su conversión precisamente en tal patrimonio el que sea descontextualizado, el que reniegue de aquella existencia anterior? ¿Cómo devolver la vida a un territorio, una vez que se lo ha confinado en el invernadero de las vitrinas del museo? ¿Cómo evitar que deje de ser, definitivamente, un producto cultural vivo si lo embalsamamos? Los vestigios culturales musealizados se convierten en nuevo escenario para el conocimiento sobre un pasado al que se da carpetazo al tiempo que se reivindica, al que cabe interpretar críticamente puesto que revela mejor que otros los errores y desventuras (también los aciertos) de nuestro mundo, no de otros. Pero es pasado, y una vez que entra en el museo, muere.

En este sentido, resulta obvio, pese a los muy variados intentos que se le conocen, que el museo no ha sido capaz de alojar este patrimonio, por tamaño, mensaje, implicaciones o por una simple cuestión de envergadura. Es el museo el que lo habita, el que ha pasado de casero a inquilino, encargado como está de poner en valor (permítaseme el galicismo algo desatinado) todo cuanto se patrimonializa. Musealizar se llama a esta operación de reinserción social, aunque en el caso del museo, su relación con el territorio se quede a menudo tan solo en un paso estratégico hacia el vislumbramiento de vastas extensiones por explorar. Aún está por dirimirse si el patrimonio etnográfico acabará por ser un mero convidado más en los museos o estos son una alternativa (o la alternativa) de una nueva y distinta existencia y esencia para un mundo que se nos está escurriendo entre los dedos. Y así, como sucede con las imágenes que nos proporciona Google Earth o el navegador de los automóviles, corremos el riesgo de obtener del territorio visiones congeladas y sin actualizar, dándolas por veraces, por actuales, como si fueran una nueva realidad a la que nos aferramos por su mayor simplicidad, accesibilidad y comodidad. Como el museo, otro placebo.

\subsection{Castilla y León, la hoja roja}

De igual manera a como sucedió en muchos territorios del país en el proceso de su conversión en Comunidades autónomas, Castilla y León sufrió (y sufre) el traumatismo de su invención, de su forja a partir de una realidad inequívocamente distinta desde casi todos los órdenes, a partir de elementos territoriales y culturales no precisados con anterioridad de esta nueva manera. El proceso autonómico, en este tipo de casos, se concibió fundamentalmente como una recreación administrativa que acabaría (o acabará, quizás) por encontrar sus señas socio-culturales de consolidación, pero que, en todo caso, respondió y responde a necesidades no señaladas prioritariamente con la vitola de la antropología, la historia o la cultura en general. Así, aparte las autonomías que sí responden a realidades de ese tipo (las llamadas de la vía rápida entonces y/o para las que 
se acuñó la expresión constitucional "nacionalidades"), existieron otras que simplemente formaron demarcaciones homogéneas demográfica, económica o geográficamente (en especial las uniprovinciales), mientas algunas otras simplemente partían y repartían viejos territorios vastos y deprimidos en demarcaciones más asumibles: es el caso de la antigua Corona de Castilla y su fragmentación en comunidades marítimas, y en dos Castillas etiquetadas la una geográficamente (C-La Mancha) y la otra poniendo de relieve la primera de sus singularidades, la unión de dos territorios históricos (y amputados) en su nombre: Castilla y León ${ }^{2}$. En este recuento sumarísimo de singularidades nos encontramos, pues, con la primera: dos personas distintas y una sola región verdadera. Una unión que, pese a no presentar trazas de conflicto equiparables a otros desajustes políticos del Reino, no deja de resultar motivo de frecuentes diatribas, movimientos sociales y, para lo que nos interesa, una distinta forma de autoproclamación identitaria y cultural que en ocasiones tiene (o debería tener) refrendo o evocación entre las paredes de los museos. No se ahondará aquí sobre los motivos que condujeron a tal amalgama, seguramente amparada en estrategias de gobierno y en cifras socio-económicas, ni sobre las operaciones de desactivación y las política de compensaciones que ello supone en algunos casos, para limar tensiones, pero sí diremos que, cuando menos, es esta Comunidad la única en que campea tal bifrontismo digno de Jano.

Aún más. Si este perfil se muestra proclive a un tipo de manifestaciones exhibitivas tradicionales y conservadoras, con un punto de vista autocomplaciente y en buena medida nostálgico, no ahonda menos en ello la necesidad de vertebrar una Comunidad autónoma que, a diferencia de otras, no cuenta con una precisa definición histórica ni con un carácter compacto y dimensional que permitiera soslayarlo. $\mathrm{O}$ sea, no es una nacionalidad en el sentido político, ni es un invento administrativo. Para abreviar, Castilla y León no es Castilla y León. No es Castilla porque esta nacionalidad histórica, si quiere situarse al nivel de las restantes del país, se extiende por un territorio multicomunitario que ha sido troceado para su mejor administración y, a partir de ahí, las estrategias emprendidas para legitimar tales decisiones, han conformado redes de clientelismo y política cultural tan tupidas que hoy día no es raro escuchar a quien se tilda de castellanomanchego habiendo nacido en Guadalajara o madrileño siendo de Aranjuez.

No es León, porque la vieja traza medieval de este Reino -la época tomada como referente para su "definición"- abarca diferentes autonomías (Galicia, Extremadura, Asturias...) y, sin embargo, los movimientos leonesistas, amparados en intentos más o menos ingenuistas de recuperación de la lengua y de autogobierno, a menudo circunscriben sus acciones a la provincia de León, una demarcación decimonónica, ignorando territorios donde no obtienen repercusión social suficiente ni representación política. Y es Castilla

2. De ahí la importancia de la "y", cuyo olvido o cambio por un guion en ocasiones enoja sobremanera a los autóctonos. 
y León porque la y griega delata un proceso de amalgamamiento inconcluso y polémico, que crea tensiones incluso lingüísticas, cuando el propio estatuto consagra engendros patronímicos como "castellanos y leoneses" para referirse a sus habitantes, o ni siquiera se atreve a otorgar oficialidad a una capitalidad de facto en Valladolid, que nadie cuestiona excepto cuando se nombra. De ahí pues que muchos de las decisiones de política cultural (y los museos como agente identitario entre ellos) se empeñen en suturar esta hendidura de la forma más discreta posible.

Siguiendo con el relato apurado de las diferencias, la geografía de Castilla y León se supone regida en primera instancia por cierta uniformidad ceñida a la cartografía. Sin embargo, ni la cuenca del Duero, ni la Meseta, ya que la orla montañosa es más bien un grueso marco que abraza su extensión, ni la campiña de valles y llanuras, ni el páramo la definen con suficiencia. Todo esto y más convierten a esta región interior en una de las más diversas. De hecho, esa diversidad tiene, obviamente, una explicación directa: el tamaño. Castilla y León descuella por dos características: es grande y está vacía. Con $94.227 \mathrm{~km}^{2}$, la región se extiende por la Meseta Norte y parte de su periferia componiendo la más vasta de las demarcaciones territoriales del Estado, y una de las mayores de la Unión europea. Pero su población, inferior ya a los dos millones y medio de personas $\left.{ }^{3}\right)$, y por tanto de densidad menor que los 27 habitantes $/ \mathrm{km}^{2}$, se encuentra a la altura de los países nórdicos, cumpliendo, al menos en este aspecto, con el tópico de las dilatadas soledades castellanas (y leonesas). Ello puede suponer una primera (y burda) explicación de cómo se configuraron sus límites y de dónde deriva tal extensión, que, obviamente, tiene que ver con la escasez de población y el hecho de haberse decantado la Comunidad casi como resultado de la previa autonomía de todas las demás regiones. Un raquítico peso demográfico que, por otro lado, hunde sus raíces en procesos históricos conocidos, no exentos de multitud de explicaciones ${ }^{4}$ y corolarios. Entre los segundos, los corolarios actuales de tal circunstancia, se pueden citar a grueso trazo, como componentes de la personalidad antropológica de la actual Comunidad autónoma, los siguientes:

- Una idiosincrasia eminentemente rural, apegada al campo y al sector primario, que aún hoy es la base de su economía y resulta la marca identificatoria de sus productos

3. 2.494 .790 a primero de año 2014 según el padrón oficial, con una oscilación anual de pérdida del $1 \%$ (25.080 habitantes), superior en 30 centésimas a la media nacional, afectada por la crisis. Aunque este último ejercicio es superada por otras, en 2013 la caída de esta región fue la más acusada, y se sitúa siempre a la cola de todas ellas, incluso cuando obtuvo discretísimos crecimientos. Sirva como referente que el aumento demográfico en un siglo ha sido escasamente de cien mil habitantes.... FUENTE: D. G. de Presupuestos y Estadística de la Junta de Castilla y León con datos del INE, "Revisión del Padrón Municipal".

4. Es debatido el arranque de este empobrecimiento en el fenómeno colonizador del continente americano, que si bien en un inicio situó a la Corona de Castilla en su conjunto como región a la vanguardia poblacional y socio-económica de la península, progresivamente la recluyó en una posición de retaguardia y definitivamente como zona deprimida desde el antiguo régimen, circunstancia que le definiría a lo largo de toda la Edad Moderna en un creciente desequilibrio respecto de las tierras costeras. 
de cara al exterior, de forma que etiquetas como "Tierra de sabor" o similares, se han colocado como las vitolas representativas de un entorno raquíticamente industrializado y a menudo por iniciativas con un fuerte componente de capital foráneo y, por ello, de escasa reinversión local. Como consecuencia, la imagen y el imaginario de Castilla y León se vinculan a esta suerte de personalidad agraria y natural (primera región en turismo rural, abanderada del patrimonio natural, etc.), lo que, independientemente de lo mucho que haya en ello de propaganda, determina una cierta dejación hacia algunas de las pautas de la modernidad (y posmodernidad) de signo urbano o cosmopolita. Castilla y León debe ser fiel a su esencia, y esta se cifra en la naturaleza, se dice. No así en lo rural, ya que si bien este es el escenario de la mayoría de la población, entendiendo como tales entornos los campesinos, pero también los de ciudades que muchas veces no llegan a conformar un auténtico espacio urbano complejo ${ }^{5}$, las políticas y los modelos a los que se aspira no dejan de ser aquellos que la propia sociedad está lejos de representar por su mera formalización social, demográfica y económica. Un contrasentido entre la realidad y el deseo, o entre las aspiraciones y su formalización, que volveremos a encontrar reflejado -cómo no- en los museos.

- El envejecimiento de la población es otro de los factores expresivos de este territorio. Un saldo vegetativo negativo que conforma una pirámide (más bien un huso) poblacional de alarmante porvenir y que, además, se acusa cuanto más hacia los márgenes, desiertos "estratégicos" o zonas de acusada depresión (el triángulo entre León, Zamora y las provincias gallegas de Lugo y Orense, es el más envejecido del país, donde la ratio trabajador-jubilado se acerca más a un temible emparejamiento). Esto afecta en especial precisamente al tejido poblacional rural, que se encuentra seriamente hipotecado de cara a un futuro en el que, o mucho cambian las tornas, o los pueblos y aldeas (en un número también superior a cualquier otra región española) se condenan al abandono y la ruina. Otro mito a punto de convertirse en realidad, el de la Castilla (y León) derruida y sola.

- Un endeble aporte demográfico externo, con un saldo migratorio negativo, y una inmigración escasa y episódica, que apenas tiene incidencia muy focalizada en determinadas áreas industriales, configura antropológicamente el territorio en este aspecto de manera marcadamente cohesionada o, en otras palabras, con una empobrecida filiación o mestizaje.

- Una sectorización económica centrada en servicios (casi el 70\%) y la función pública, con escasa implantación industrial (cerca del 15\%), y una ciudadanía con un perfil político conservador (sucesivos gobiernos de derechas desde 1987, con mayorías absolutas consolidadas las más de las veces) y una marcada tendencia a cierto conformismo o resignación completa el apurado cuadro.

5. Exactamente el 50\% de los castellanos y leoneses viven en núcleos de población inferiores a 20.000 habitantes, si es que tal puede ser el listón para hablar de ciudad en un entorno de este tipo, con nueve capitales de provincia de las que ninguna se acerca al medio millón, y sólo una supera los 200.000. 
En definitiva, con estos datos distintivos, Castilla y León se nos ofrece como una región deprimida, envejecida y en cierto modo paralizada; marco ideal para musealizaciones de corte tradicionalista como las que veremos a continuación $y$, en especial, tierra de promisión para la etnografía y una manera museística de entender el patrimonio.

\subsection{Museos en Castilla y León: Parábola del náufrago}

Suele juzgarse a los museos con poca ecuanimidad y, a veces, sin neutralidad. O se juzga lo que hacen en comparación con otros que, a buen seguro, no tienen los mismos medios ni las mismas opciones, o se juzga solo una parte de su actividad, olvidando el resto de su cometido, habitualmente el menos visible. Teniendo esta precaución en cuenta, lo que aquí se dirá sobre ellos no pretende dictámenes globales o decisivos, sino únicamente una apreciación sobre la parte expuesta del museo, aquella que se expone -en su doble acepción- al escrutinio público: hablaremos de lo que se cuenta y de cómo se cuenta. Y, por supuesto, no presuponemos que los defectos, si los hubiere, sean responsabilidad del propio museo, pues, como es bien notorio, y salvo excepciones contadísimas, los museos no son organismos autónomos ni toman sus propias decisiones, y hasta puede afirmarse que a veces funcionan correctamente a pesar de quienes las toman.

Otra cosa es juzgar a quienes definen sus comportamientos a gran escala. Y tratándose, como es el caso de Castilla y León, de gobiernos del mismo signo político casi en la práctica totalidad de su decurso autonómico, se requeriría de él una política destinada a algo más. Dos leyes de museos (1994 y 2014) y dos fundaciones (de promoción de las artes $\mathrm{y}$ de patrimonio) que, sin embargo ofrecen un pobre balance en este aspecto (como en otros). No se ha desarrollado el articulado de las primeras para crear auténticos sistemas o redes con comportamientos sinérgicos, no se han implementado los medios materiales y humanos que se prometían con tales reformas legislativas, no ha habido un rumbo, y sí parches y alguna que otra zozobra fruto de la imprevisión y la menesterosidad. Otra cosa ha sucedido en el terreno fundacional, el reservado a los mejores medios y las opciones políticamente más favorecidas. Allí, en ambos casos, las opciones han sido casi siempre las novedades (museos regionales, aulas arqueológicas, centros de interpretación...), dejando al margen los proyectos y las realidades de otros, por interesantes que fueran y necesitados que estuvieran de apoyo, y la posibilidad de articular nuevos contenidos en lugar de, simplemente, nuevos contenedores. Nihil novum sub sole.

\section{MUSEOS ETNOGRÁFICOS EN CASTILLA Y LEÓN: LA SOMBRA DEL CIPRÉS}

Hace exactamente veinte años, un colega y yo mismo abordábamos este mismo asunto de una manera circunstancial, al hilo de una invitación similar ${ }^{6} \mathrm{y}$ apuntábamos algunas de las variables que, tal vez, no sea mala idea comprobar. Decíamos entonces que más allá de los

6. Alonso y Grau, 1995. También, Grau, 1998 y 2009 y más recientemente Celis, en "Museografía y etnografía en el ámbito de la provincia: el caso de León, en Alonso, Díaz y Piñel, 2008, pp. 41-54. 
rigores taxonómicos del ICOM, las "eternas crisálidas" (parafraseando a Julio Caro) que eran la gran mayoría de los museos llamados etnográficos, estaban más cerca de la idea de colección exhibida (y exhibicionista) que de la de museo y, en ocasiones, apenas llegaban a la de "conjunto de objetos en desuso", rememorando las Wünderkammer, en una singular parábola histórica que dice mucho acerca de la pervivencia de las museografías como representantes más de una actitud (y sus referentes epocales) que de una época. "Muchos de nuestros "museos etnográficos" son el reducto fragmentario de la nostalgia, la pesadumbre de un pasado trastocado en Edad de Oro por las saudades bienintencionados de un individuo o de una comunidad". Y así seguimos. Como se verá, ese panorama museístico continúa ofreciendo tales pautas: una colección privada o colectiva fruto del entusiasmo y la alerta por especímenes en vías de extinción, por el intento, en general, de poner puertas al campo, para encerrarlo en unas estancias que recogieran fósiles-guía de una forma de vida a punto de fenecer. Poco o mucho después, los poderes públicos, llamados a revelarse como agentes de institucionalización en diverso grado; en general, ayuntamientos, a veces diputaciones, e incluso, en el caso del gran museo etnográfico regional, el gobierno autonómico (que museificó una colección nacida de esta misma manera, aunque al cobijo de una entidad de ahorro). Sí cabe afirmar, en cualquier caso, que precisamente esa institucionalización ha permitido afianzar lo que, hace un par de décadas, eran proyectos endebles, ya que la sanción institucional ha convertido en permanentes esas colecciones de añoranzas apiladas en caserones añejos, que, adquiriendo una tutela económica y un apoyo oficial (no siempre sólido o continuado) han logrado eludir un destino funesto que se ha llevado a algunos de los que no lo han conseguido ${ }^{7}$. De cualquier manera, poco ha cambiado lo demás, y deberemos hablar más de cantidad que calidad u otras categorías.

En 2003, un atinado recuento libresco ${ }^{8}$ daba cuenta de cerca de una treintena de centros declaradamente etnográficos en la región (una decena más, si desglosamos pequeños centros agrupados). Este año 2015, el conteo de la propia administración, que incluye centros no estrictamente amparados por la propia definición legal de museo ni siquiera con un criterio expreso que no sea la mera enumeración, alcanza el centenar. Es por tales motivos que la ratio de museos en esta región, según la estadística ministerial, ofrece tal suntuosidad, cercana a ocho por cada cien mil habitantes, en niveles aparentemente envidiables ${ }^{9}$. Sin embargo, esa cifra tiene más que ver, evidentemente, con la ínfima densidad de población (y con la modestia de muchos "museos") que con una auténtica infraestructura cultural, extraña a los logros de la administración autonómica, más centrada en proyectos de

7. Museos como el de Benigno Eiriz, en Alija del Infantado, por ejemplo, o el del Carro en Villanueva de Valdueza (ambos en León), han caído sin que se sepa fehacientemente su destino. Otros, aún resisten en manos privadas pese a la indiferencia pública, como el de El Varal, en Carracedo del Monasterio, meritorio empeño de don Antonio Sernández.

8. Fernández, J.J., 2003. La estadística ministerial reciente abunda en esa cifra antigua, pero no recaba datos de la mayoría de los censados "extraoficialmente".

9. Estadística de museos del Ministerio de Educación, Cultura y Deporte, 2012 (la cifra sólo es superada por la ciudad autónoma de Melilla). 
relumbrón a gran escala que en la imprimación del territorio con una auténtica red trabada y efectiva. Este fenómeno, el de la precarización de medios y recursos de forma paralela a la proliferación de museos, tal y como lo describe Rafael Azuar en su reciente estudio (2013), afecta a todos los museos del país, pero en el caso de los etnográficos conforma un precariado aún más evidente.

En todo caso, podemos comenzar por un intento de subdivisión, que mezcle lo cronológico (o epocal) con lo formal, de manera que probamos cuatro grupos: uno sobre el trato recibido por este tema en la museología previa o no exclusivamente dedicada a él; un segundo por aquellos primeros (y pioneros) museos etnográficos fruto del ánimo popular y la alarma conservacionista; un tercero compuesto por los proyectos abordados por las administraciones tutelares (y titulares) y un cuatro y final por aquellos que conforman curiosidades, rarezas y algún sendero sin explorar digno de mayores abundamientos.

Lógicamente el espíritu de cada momento (una suerte de zeitgeist museístico) alumbra cada uno de ellos con pautas reconocibles, de ahí que, si no mencionamos a todos, algo que haría este excurso más pesado e improductivo, sí al menos intentemos caracterizarlos aludiendo a ejemplos representativos.

\subsection{Avant la lettre: antropología en los museos arqueológicos y provinciales. El camino}

Hubo un tiempo, un largo y a menudo mezquino tiempo, en que sólo existían museos provinciales. O casi. El bagaje y trayectoria hermana de esos museos en todo el país nos ahorran muchas explicaciones (Bolaños, 1997), pero sí cabe aludir, al menos, a su papel en la conformación de lo que podríamos denominar las pautas de la consideración museística de la etnografía, pues ellos marcarían la senda para su musealización (como ejemplo o como contramodelo) habida cuenta de que la etnografía era (y a veces aún es) una pata de ese trípode en que dicen asentar las lecturas de los territorios de que son testigos e imagen.

En sus salas y vitrinas encontramos frecuentes secciones con esta vitola, a menudo sencillas presentaciones de enseres de una cultura popular recién cancelada, evocada a partir de sus artefactos más característicos y "típicos" tratados como exhibitorios de fósiles -o causas perdidas-, de idéntica manera a como se trata al patrimonio arqueológico, perspectiva prevaleciente en ellos (por formación de sus técnicos y por vocación de sus trabajos más relevantes), es decir, meros trasuntos tipológicos demostrativos y analíticos. ¿Mera etnografía? En este esquema general, hay distingos, por supuesto. El de Ávila es un museo que aún conserva de forma destacada esa vocación, pese a que sus limitaciones de espacio y medios le impidan desarrollarla como seña diferencial. Algunos otros, apenas le dedican atención ya o, más coherentemente con sus posibilidades, han incluido este tipo de bienes en un relato más homogéneo en que la llamada cultura material tradicional se inserta con naturalidad en un discurso histórico-cultural más acorde con los tiempos y las museologías. En todo caso, sirva la alusión a este primer paso para entender la hipoteca 
hermenéutica que hace de los etnográficos una suerte de hijuela de los decimonónicos provinciales, con sus defectos y virtudes.

\subsection{Primera hornada, de la nostalgia y el folclorismo. Un mundo que agoniza}

Más allá del escaso refrendo que la perspectiva antropológica (y hasta la etnográfica) ha tenido en esos museos provinciales, los más antiguos del país como conjunto, las propias provincias empezaron a musealizarse precisamente con estos, con los etnográficos. Y lo hicieron gracias a una primera hornada de museos dedicados a contener el inexorable y precipitado derrumbamiento de la cultura tradicional, merced en especial al desarrollismo de los sesenta y a la crisis de los setenta, acicates ambos del final del mundo rural tal como había sido conocido casi desde el neolítico. Fue en esas décadas cruciales de la historia del país cuando arrancó un fenómeno que se benefició del auge de los museos en los años 80 y principios de los noventa, hasta que la ley regional de 1994 vino a dar carta de naturaleza a estos proyectos. Hasta entonces, ciudadanos y grupos, a veces amparados o socorridos a posteriori por las autoridades locales, se dedicaron a recoger y custodiar los testimonios materiales de esas vivencias campesinas o vinculadas a la actividad primaria, tan en desuso como cercanas, en una suerte de fosilización de un pretérito imperfecto que aún no se había adentrado por las sendas de un posible aprovechamiento turístico. Se trataba, simplemente, de conservar lo propio. Ahí es nada.

Con tan menguados medioscomoescaso apoyo técnico, los resultadosfueron cuestionables con los criterios de hogaño, pero para lo que fuera antaño, su labor ha permitido diligencias museísticas que otros quisieran ahora. Los montajes, como corresponde a estadios primitivos de aplicación de conceptos museológicos, derivaron en meras aglomeraciones de material, simples exhibiciones de riqueza patrimonial arracimada en centones desorganizados o con una sumaria vocación exhibitiva formalmente primaria y muy pocas veces dotada de medidas correctivas, preservativas o de otro tipo. Se trataba, como en los primeros tiempos de la museística que citan los manuales, de meros tesoros de la vida que se escapaba entre las manos. Eran sus tesoros, sus wünderkammer. Pero el mero hecho de que lo fueran ya establecía una categoría nueva: la etnografía merecía formar museos, autónomamente.

Lamentablemente, estos pequeños rescoldos de una nostalgia bien entendida y voluntariosa no merecieron en principio demasiada atención por parte institucional, recelosa siempre la administración regional a amparar proyectos no nacidos en su seno, y por otro lado, poco nuevo comprobamos en los modernos museos del ramo, cuando apenas se han permitido efectuar similares planteamientos discursivos aunque, eso sí, con unos medios señaladamente superiores.

Como comprobábamos hace dos décadas, los museos de base siguen ofreciendo la cara más amableysugestiva deestefenómeno. Son, además, pequeños “museos” delentornoinmediato, exponentes de una llamada "cultura material" que es más "el material para una cultura". Son embriones de lo que podría ser una red de centros de este tipo bien entendida si se supiera 
pensar a escala territorial y no dejar simplemente que cada palo aguante su propia vela. Son una oportunidad que, aún, no se ha aprovechado, pero tampoco se ha perdido. Su perfil, englobado bajo la etiqueta "etnográfico", lo caracteriza como centros generalistas, dedicados a la recolección de objetos que han dejado de ser viejos para ser antiguos, arracimados en caserones, casas de cultura, salas polivalentes, escuelas cerradas o vestíbulos municipales. Su dispersión, irregular y concentrada, subrayaba desde hace años dos provincias con más de la mitad de los centros: Soria y León, extremos duros ambos (VV.AA., 1993 y Ruiz, 1991). Los museos rurales de Soria (Abioncillo de Calatañazor, Alcubilla, Barca, Monteagudo de las Vicarías, Ólvega, Sarnago...), con alguna veleidad de ecomuseo (Molino de los ojos en San Esteban de Gormaz) y los leoneses, que añaden una vocación comarcalista (Bierzo alto en Bembibre, Valle del Bernesga en Lorenzana, de Castrocalbón, Riaño, Casares de Arbás, Prioro o La Ercina), son punta de lanza de un fenómeno extendido a Ávila (Navalperal de Pinares, Padiernos, Pedro Bernardo, Gotarrendura) Burgos (Castrojeriz, Los Balbases, Hontoria de Valdearados, Montejo de San Miguel, Villadiego), Palencia (Autilla del Pino, Cervera de Pisuerga, Frómista, parte de la colección Fontaneda en Ampudia), Salamanca (Navasfrías, Puerto Seguro), Segovia (Cantalejo, Otones de Benjumea), Valladolid (Alaejos, Cogeces del Monte, Curiel de Duero, Fresno el Viejo, Tordehumos, La Zarza) o Zamora (Codesal, Manzanal del Barco, Moreruela de Tábara, Rabanales de Aliste) y manifiestan un fenómeno expansivo que aún reclama una política regional que pula, fije y dé esplendor.

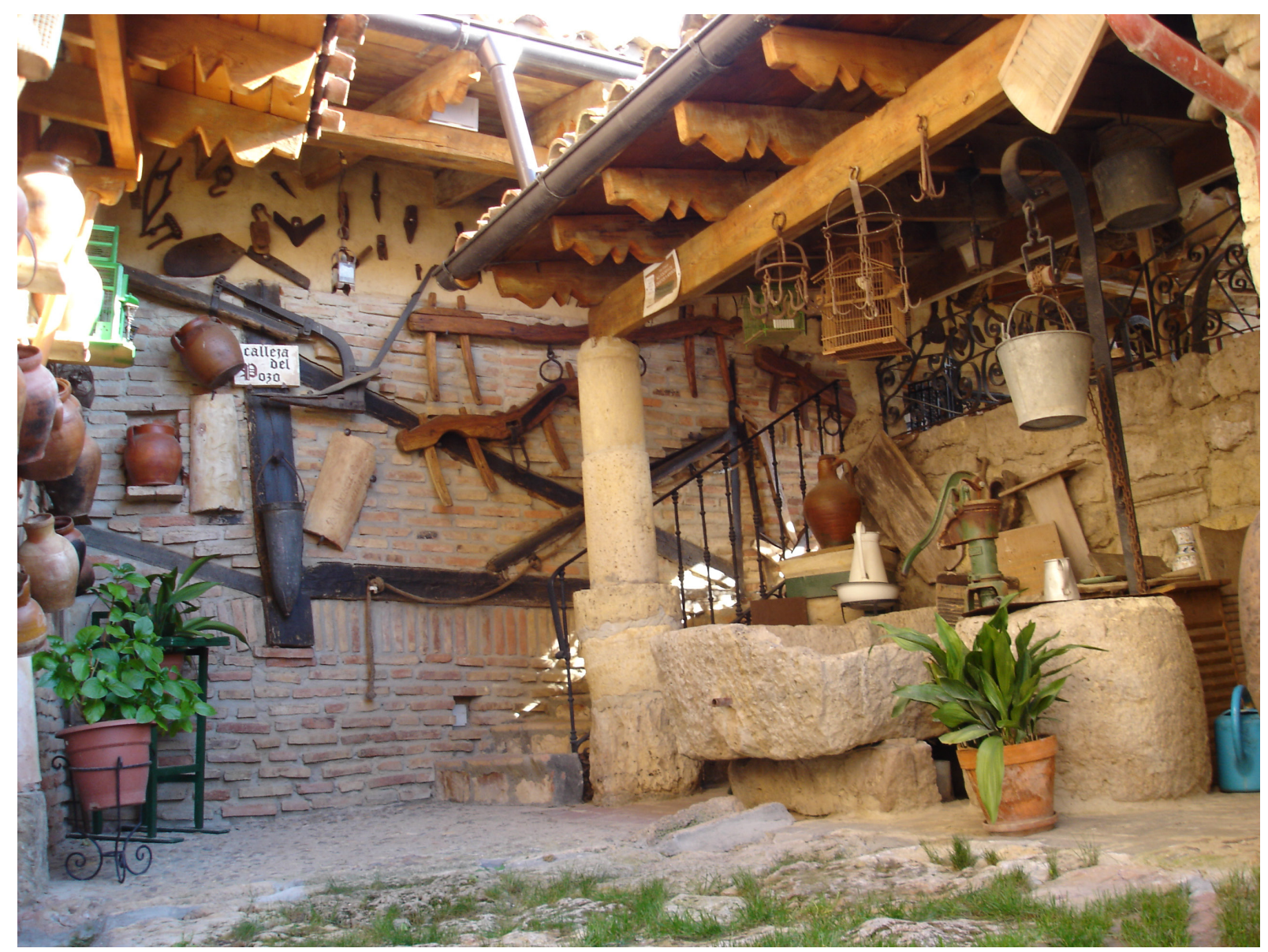

Foto 1: Museo etnográfico de Frómista (Palencia). Foto gentileza de Santiago Peral. 


\subsection{Segunda hornada e institucionalización. El príncipe destronado}

Quizás no fuera casual que la primera gran decisión materializada en materia museística de la Comunidad autónoma tenga relación con este asunto: la creación del Museo Etnográfico de Castilla y León, primero de los de ámbito regional. Anunciado por la Ley 10/1994, de 8 de julio (BOCyL de 13 de julio de 1994), de Museos de Castilla y León, en su artículo 11, este centro fue concebido para albergar la más completa colección meseteña de etnografía, atesorada por la extinta Caja España (a su vez antigua iniciativa de la caja de ahorros zamorana), cuya titularidad, por cierto, no está muy clara aún en ese aspecto $^{10} \ldots$ En todo caso, la apertura a partir de 2002 de este Museo inició una política de creación de centros museísticos de escala regional y titularidad autonómica (bien que adscritos a una Fundación para su gobierno $)^{11}$ que había de vertebrar una serie de discursos deficitarios o acordes con la idiosincrasia de la Autonomía. Aunque la disponibilidad de una colección excelente lo permitiera, no debió ser, por tanto, contingente que Castilla y León comenzara por definirse "etnográficamente". Desde aquel año, el Museo no ha cambiado demasiado, y ofrece un guión temático, basado en capítulos donde se va desgranando una visión sectorializada y bien ilustrada por objetos de cada apartado. El barro, el alma y el cuerpo, la forma y el diseño, el tiempo y los ritos, el espacio y el entorno, componen (salvo el primero de ellos, que deviene un tanto forzado por la idiosincrasia de las colecciones) parejas que se pretenden complementarias y dialécticas, y cuyos espacios se subdividen a su vez en distintos temas subyacentes, no siempre suficientemente $\operatorname{articulados}^{12}$. Sirva como crítica constructiva que no existe una fórmula introductiva a su visita (que se inicia abrupta y sorpresivamente por esa gran muestra cerámica: "el barro") y que apenas se formaliza un perfil distintivo de la región o de las regiones en ella existentes a partir de las colecciones, sino que estas sirven para ilustrar esas secciones como una suerte de museos independientes dentro del mismo contenedor. La propuesta expositiva, por tanto, reitera modelos algo gastados ya sobre las acciones del ser humano, sin concretar singularidades más allá de las derivadas de la contemplación de las piezas, que, no contrastándose con

10. La desaparición de las cajas de ahorros ha dejado en cierto limbo su rico patrimonio cultural y monumental acerca de su propiedad. Por otra parte, la creación de este gran museo regional de etnografía estuvo sobrevolada por un conflicto que enfrentó fórmulas de gestión y formas de entender esa musealización (abanderada por la Asociación de antropología de Castilla y León "Michael Kenny"), que en lugar de remediarse, sencillamente se acalló. Ver http://www.antropologiacastillayleon.org/ [Consultado el 8 de abril de 2015].

11. Vinieron después los MUSAC (León), Museo de la minería y la siderurgia de Castilla y León (Sabero, León) y Museo de la Evolución Humana (Burgos), regidos por la Fundación Siglo para las artes de Castilla y León.

12. VV.AA., 2004, Celis, "Museografía y etnografía en el ámbito de la provincia: el caso de León, en Alonso, Díaz y Piñel, 2008, pp. 41-54. y http://www.museo-etnografico.com/areaexpo.php [Consultado el 8 de abril de 2015]. 
otras, no la evidencian. El relato, así mismo, como suele en estos casos, tiende a las fotos fijas y algo sepias y, tal vez, valdría para demasiados casos.

Por otro lado, su trayectoria previsible como centro de referencia en los museos de este tipo tampoco ha dado los frutos que, tal vez, se esperaban. Limitado por sus medios (pese a contar con presupuestos para actividades muy superiores a la media de los museos y a una fórmula de gestión supuestamente más ágil...), desarrolla un amplio y acertado programa de actividades de todo tipo, pero en demasía ceñido a puertas adentro, lo que le convierte en otro museo más, pese a su gran tamaño y supuesta jerarquía territorial. Algo así sucede con los demás centros regionales, que no están en la región, aunque se pretenda que la región sí esté en ellos. Además, en este caso, y demasiado pronto, las atenciones del gobierno regional se encaminaron a nuevos proyectos de relumbrón ${ }^{13}$, y el museo de las gentes de Castilla y león fue destronado, tal vez prematuramente.

No lejos en planteamiento y configuración, aunque más reciente, destaca el Museo etnográfico Provincial de León, abierto en 2008, formalización moderna de un viejo museo con más de medio siglo de trayectoria expositiva y casi uno como propuesta ${ }^{14}$, maltratado en sus antiguas instalaciones durante décadas, que solo este proyecto ha podido encarnar en su auténtica valía. La decisión de su titular, en este caso la Diputación provincial, fue arriesgada y original por ubicarlo fuera de la capital, en el convento de San Agustín (siglo XVI), levantado para la ocasión de su casi total ruina, sito en pleno camino de Santiago en la localidad de Mansilla de las Mulas, a una docena de kilómetros de la ciudad de León. Con un planteamiento clásico de museo de artes populares o tradicionales pero con variantes que animan su conformación discursiva y museográfica ${ }^{15}$, recurre a los consabidos esquemas funcionales que dan en retratos fijos de tipo temático, mezclados con cierta caracterización comarcal de las tierras leonesas, especialmente en su arquitectura popular. Nada nuevo, pese a que el resultado deviene atrayente apoyado en una museografía de postín $y$, también, en un laborioso programa de acciones museísticas.

13. El MUSAC o Museo de Arte contemporáneo de Castilla y León fue el primer sustituto. Abierto en 2005, su apuesta por ser un museo del puro presente daba una vuelta de timón a las preferencias en materia de política museística de la Comunidad. Desde entonces, la etnografía ha seguido siendo esa hermana pobre que fue...

14. Es uno de los poquísimos proyectos tan longevos (con sus consiguientes azares), pues remonta sus orígenes a una propuesta de 1918 por lograr un Museo leonés de antropología y etnografía (sic).

15. Celis, 2009 y http://www.etnoleon.com/ [Consultado el 8 de abril de 2015]. 


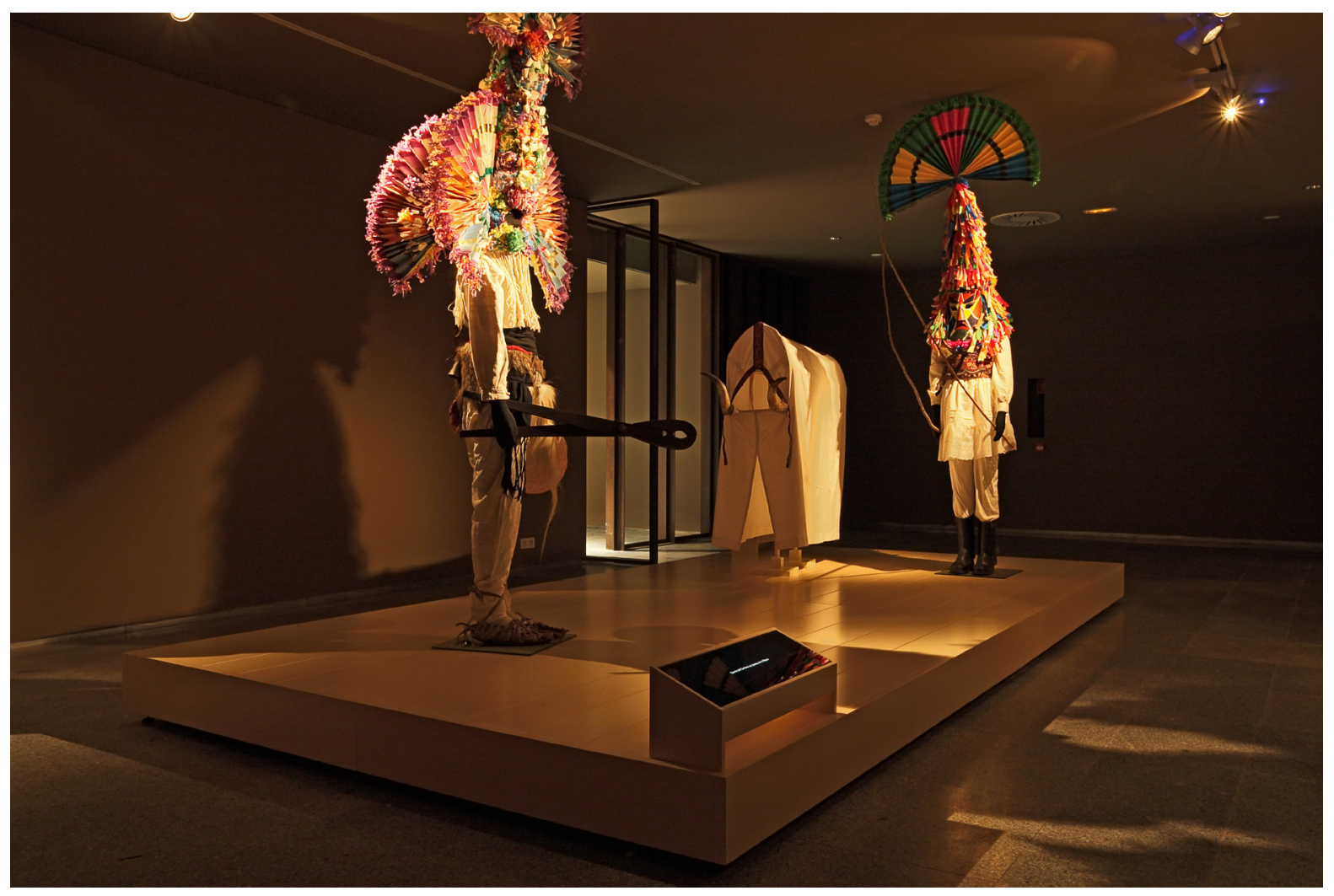

Foto 2: Museo etnográfico de León en Mansilla de las Mulas

Esta segunda oleada de museos locales, activados ahora por los ayuntamientos (con el apoyo de las diputaciones provinciales) en busca de una oferta cultural distintiva, se caracteriza por una decantación hacia lo temático, hacia un leitmotiv característico, capaz de representar a una localidad o comarca mediante metonimia, por la concentración en uno de sus rasgos particulares. Rasgos que, en la mayoría de los casos, suponen abandonadas actividades económicas o tradiciones en declive, de tal forma que no constituyen más novedad que la de renunciar a una generalidad o totalidad inviable para centrarse en un aspecto de tan específico, a veces rayano la hipérbole. Como novedad, destaca que en ciertos casos suelen recuperar edificios o instalaciones en desuso (relacionadas o no con el tema), convirtiendo la solución museística en una herramienta para la preservación de un patrimonio no solamente mueble. Algunos ejemplos, sin ánimo de exhaustividad, podrían ser: los museos del cereal en Arévalo, del juguete de hojalata en Candeleda (ambos en Ávila); de exvotos en Buezo, de las ferrerías en Barbadillo de Herreros, de pasiegos en Espinosa de los Monteros, de cerámica en Aranda (en Burgos); del pastor en Barrios de Luna, del chocolate en Astorga, el Batán-museo en Val de San Lorenzo, el alfar-museo de Jiménez de Jamuz, del chocolate y molinos en Castrocontrigo, del botijo en Toral de los Guzmanes, de la alubia en La Bañeza, de la mosca de las artes de pesca en Soto de la Vega (en León); minero en Barruelo, del palomar en Santoyo y de Tierra de Campos en 
Paredes de Nava (Palencia); del traje en La Alberca, apícola en Arapiles, taurino en Béjar y Salamanca, textil en Lumbrales, chacinero de Guijuelo, del aceite en San Felices de los Gallegos, del lino en Peñaparda y del orinal en Ciudad Rodrigo (Salamanca); del paloteo en San Pedro de Gaillos, del molino en Matamala, y del martinete de Navafría en esa localidad (Segovia); de la resina en Matamala de Almazán, de la cerámica en Quintana Redonda o del Acebo en Torrearévalo (Soria); del vino en Peñafiel y del pan en Mayorga de Campos, taurino en Valdestillas, del encaje en Tordesillas, del calzado en Villalón de Campos, de la carpintería en Villalba de los Alcores, del cántaro en Valoria la Buena y del pastor en Montealegre (Valladolid) y del azúcar en Villanueva del Azoague, de gigantes y cabezudos en Puebla de Sanabria o de la alfarería en Muelas del Pan (Zamora). Y etcétera, por supuesto.

Citemos a la sazón, para terminar, uno de las últimas incorporaciones a este panorama de ámbito comarcal y tutela municipal: el Museo de las alhajas en la Vía de la Plata (La Bañeza, León), abierto desde 2011 y provisto de una nueva vuelta de tuerca a la habitual exhibición tipológica y funcional de una, por otra parte, competente colección privada de joyería e indumentaria de tierras del sur leonés y norte zamorano donde, como vemos, se concentran algunas de las propuestas más nutridas ( $\mathrm{y}$ tal vez algo redundantes) de este tipo. Una muesca más.

Entre las más interesantes alternativas cabe señalar las efectuadas por la Diputación leonesa en tres emplazamientos de gran interés y personalidad etnográfica, convertidos en museos -imusealizados?- de forma poco intervencionista y con resultados tan modestos como ajustados a la escala, de ahí su éxito y de ahí sus carácter (creemos) ejemplar. Se trata del Alfar-Museo (nótese la preeminencia verbal) de Jiménez de Jamuz, instalación que conserva el único alfar tradicional de la zona ceramista jiminiega, la única con perfil propio aún en tierras leonesas, y lo conserva vivo, con cocciones periódicas y un artesano al frente; el Batán-Museo de Val de San Lorenzo, reflejo de la actividad pañera de la zona somoceña (completado con el Museo textil de La Comunal, instalación más clásica sobre la industria del ramo ${ }^{16}$ y el Museo de la Arriería de Santiago Millas ${ }^{17}$, suficiente testimonio de esta actividad singular en el corazón de la llamada Maragatería. Todos ellos beben modestamente de la idea del ecomuseo, transformada en sucinta y conservacionista operación de ajustado presupuesto, tutelados en red por la diputación provincial y a cargo de autoridades locales, enraizados en su terruño, al servicio de propios y extraños. Así sí.

16. http://www.aytovaldesanlorenzo.es/turismo-y-ocio/Lugares_de_Interes/El_Batan.html [Consultado el 8 de abril de 2015].

17. http://www.aytosantiagomillas.es/turismo-y-ocio/museo/ [Consultado el 8 de abril de 2015]. 
Y, por supuesto, otro caso singular: la Fundación Joaquín Díaz, en Urueña (Valladolid). Si aquellos museos leoneses probaban suerte en el terreno de la siembra in extenso, esta lo hace en la intensidad, concentrando sus esfuerzos museísticos y culturales en una villa bendecida por su ubicación, patrimonio, perfil y una decidida política de la diputación en pos de su conversión en centro irradiador de cultura. Fue el afamado etnógrafo quien comenzó, con su colección museística y frecuentes y trabajadas muestras temporales. Y siguieron muchos: el Museo de campanas, el de instrumentos musicales del mundo de Luis Delgado...y finalmente la Villa del Libro. Lástima que se trate de una excepción que, eso sí, es un ejemplo (Veleda, 2003).

\subsection{Otras perspectivas: museos de las crisis postindustriales y algunos raros y curiosos.}

\section{Las guerras de nuestros antepasados}

De entre el normalizado y algo plano panorama que describimos, es preciso sustraer algunas propuestas distintas y distintivas, en potencia o en acto. La primera de ellas, quizás la más desarrollada es la arqueología industrial. De las herrerías bercianas al canal de Castilla, pasando por el ferrocarril o las industrias de derivados agrícolas, esta región ofrece opciones para articular recorridos y redes colaborativas que señalen los interesantes fenómenos antropológicos e históricos vinculados a ellas. Y aunque en estos centros se viene a tratar el asunto a imagen y semejanza de lo que sucede en los dedicados a la labranza, o las actividades tradicionales, bien es cierto que su vinculación con elementos del paisaje, del territorio, a mayor escala, como son los inmuebles e infraestructuras industriales, deviene una opción más acorde con la apertura de caminos por explorar.

Un “gran proyecto" autonómico debe traerse a colación en este momento: El Museo regional de la siderurgia y la minería en Sabero, inaugurado en 2008. Este museo sufrió una génesis tortuosa, con episodios de auténtico desatino y un final aún no conclusivo, solucionados a golpe de talonario en los últimos veinte años. Nacido al calor de una modestísima y digna sala descriptiva sobre la vocación de esta comarca minera, la reconversión y cierre, en 1991, de las actividades industriales, provocaron la alimentación de una expectativa de salida en el ámbito de los ecomuseos o, al menos, de la habilitación de su amplio y original patrimonio industrial para disfrute público de propios y extraños. Sin embargo, un proyecto mal programado desde el inicio, pese a los consejos técnicos, actuaciones inexplicables como la espantada de la empresa minera sin mayores compromisos, la pérdida, deterioro o simple expolio del material mueble e inmueble, la ejecución de arquitecturas espurias e inútiles sin programa funcional alguno y la confluencia de dos Consejerías no muy coordinadas, provocó en su día la reducción -momentánea aseguran- del proyecto a la ocupación de la lonja de laminación, la ferrería de San Blas, 
único BIC de la zona (Balboa, 2006; García Castellón, 1997), con una instalación temática dedicada al mundo siderúrgico-minero que, eso sí, cuenta con uno de los presupuestos más holgados de la región para actividades promocionales. Sin embargo, en el interior de este soberbio espacio patrimonial podemos contemplar maquinaria rehecha (la original no se conservó) y prolijos datos técnicos o ambientales sobre la minería en el valle (poco en realidad de ámbito regional...), pero, por revelar claves de su contenido (no diseñado por ningún museólogo que esté al cargo en la actualidad), nada acerca del proceso de crisis y desmantelamiento social que supuso el cierre de la mina. Ni una palabra sobre ese acontecimiento antropológico de primera magnitud en la zona. Un acontecimiento, tal vez, políticamente incómodo... En resumen: una muestra sobre la minería, pero no sobre los mineros y la sociedad de la mina ${ }^{18}$. Un museo que debería ser referente de este tipo de oportunidades en el territorio, condenado, una vez más, al ensimismamiento y la corrección.

En este marco, destacan así mismo los proyectos vinculados a la industria harinera y el Canal: Museos de la fábrica de harinas de San Antonio en Medina de Rioseco, Centro de interpretación del canal de Castilla en Herrera de Pisuerga o el reciente MIHACALE (ostentoso y desacertado nombre para la harinera más modesta de la región: Museo de la Industria Harinera de Castilla y León) abierto en Gordoncillo (León), que se beneficia de la cercanía del Museo del Pan, en la localidad vallisoletana de Mayorga de Campos. Un trabajo en red de todos estos centros dispersos en el territorio regional facultaría nuevas acciones que enriquecerían a todos ${ }^{19}$. Más aún si contamos en Castilla y León con uno de los proyectos estrella de la museística estatal: el Museo nacional de la Energía, ubicado en las instalaciones de la MSP ponferradina. Lastrado por su inconclusión y por la amputación de su vertiente investigadora con el cambio de gobierno, este museo se instaló en las piranesianas ruinas de la industria térmica y ofrece de momento muy escasa repercusión territorial, centrado en el funcionamiento de su parte abierta al público y en proyectos (eso sí) de calado social y antropológico aún en desarrollo (testimonios de mineros, etc.) que pudieran tener proyección futura si se lo permite quien debiera.

Existen, por fin, algunos museos que no se dedican expresamente a este tema pero que -como es obvio- participan de él. Cabría señalar algunos por su singularidad, como el Museo Sierra-Pambley (Gamoneda, 2006), que aparte de su carácter de excepcional casamuseo de época dedica espacios a la labor pedagógica y filantrópica del Institucionismo y su papel en León en los años finales del XIX y arranque del XX, seccionado por la

18. http://www.museosm.com [Consultado el 8 de abril de 2015].

19. Aunque la ley de 1994 y la de 2014 hablan de Sistemas y redes regionales, poco se ha avanzado en este sentido. Sobre el trabajo en red: Grau, 2007. 
dictadura. Y, por fin, museos históricos con fuerte componente antropológica, los "museos de los otros", fruto de una mirada colonialista que sería preciso corregir y aprovechar en el marco de nuevas lecturas. Me refiero a los de arte oriental abulense y vallisoletano, rescoldos exógenos de la actividad misionera.

\section{3. ¿EL FUTURO YA ESTÁ AQUÍ? VIVIR AL DÍA}

Tras veinte años de la anterior, Castilla y León acaba de dotarse de una nueva ley de Museos $^{20}$. Es notorio el furor legislativo, en esta como en otras materias, que recorre las Comunidades autónomas. Dos leyes en veinte años deberían traslucir o un fracaso de la primera o un cambio de panorama radical que justifique la segunda. A esta última causa se alude en la ley para justificarla, pero no se efectúa análisis ni diagnóstico alguno que lo argumente, por lo que uno se siente inclinado a pensar en el primer motivo, confirmado cuando se evidencian las escasísimas aportaciones del nuevo texto y los aún menores logros de la anterior ley en su prometedores párrafos.

De hecho, la primera de las carencias a gran escala que detectamos en este apretadísimo e inabarcable panorama es esa: la de un conocimiento y evaluación de los recursos museísticos disponibles. Para ello, tal vez el gran museo autonómico u otro organismo podría encabezar un trabajo de investigación y evaluación de la estructura del Patrimonio etnográfico regional vertido en imagen pública museística: qué hay, cómo está, y qué se cuenta y se podría contar con él. Incluso podría reconsiderarse la posibilidad de que dos de esos museos (los de mayor envergadura, ya citados) respondieran a la dualidad histórica de la región, aunque, si se quiere, como paso previo, los museos provinciales podrían ocuparse de esa tutela siempre y cuando contasen con medios que en absoluto tiene a la sazón. Algo como lo que sugiere la ley de museos, pero llevándolo a cabo. Centros comarcales podrían armar este esquema de trabajo. A él habría que añadir, en directa conexión con el o los centros regionales, los museos monográficos, los industriales y, en su caso, ecomuseos, centros interpretativos... En fin, un auténtico sistema trabado que ya proponíamos hace veinte años.

Eso en lo externo, pero en lo interno -y dejando aparte el tema de los recursos ${ }^{21}$ - quizás el déficit más inmediato en la configuración de los museos etnográficos sea el relacionado

20. Ley 2/2014, de 28 de marzo, de Centros Museísticos de Castilla y León.

21. Apenas un etnógrafo como tal en la plantilla técnica de la administración (aunque haya que sumar los que sirven en el Etnográfico regional, pues la Fundación de la que depende no es sino una parte de la administración "externalizada a medida") y ninguna otra infraestructura estable destinada a tales cometidos, pese a tanta palabrería sobre su valor. 
con sus discursos, con el planteamiento de sus relatos acerca de la antropología, acerca de los individuos y colectivos que están detrás ("dentro" diríamos) de los objetos que muestran. No hay en esos museos (salvo excepciones) más que una suerte de nostalgia idealizada, una especie de etnomelancolía bienpensante y algo costumbrista que renuncia, expresa o inconscientemente, a relatar críticamente el pasado. No hay en ellos (salvo excepciones, insisto), nueva museología ni museología crítica (sea ésta epígono o hijastra de aquella). Nada sobre las contradicciones y el fin de esas sociedades, sobre porqué desaparecieron y el balance de ese tránsito; nada sobre las personas donde hay tanto sobre lo que crearon con sus manos. En definitiva, demasiada ortodoxia y tradición en los propios planteamientos museológicos, posiblemente derivados de falta de reflexión sobre los mismos, habida cuenta de la carencia de personal especializado en la gran mayoría de los centros locales de este tipo, y posiblemente fruto también de la huella que ha dejado esa institucionalización tan reciente y frágil, en discursos convocados para esquivar posturas críticas.

El recurso a modelos expositivos basados en este museo etnográfico meramente acumulativo, mostrativo y lineal provoca la asunción acrítica de una manera de exponer, convertida en canónica y durable ${ }^{22}$. Veamos un ejemplo ilustrativo, para concluir. En el Parque natural del lago de Sanabria y alrededores existen dos centros de interpretación: uno de ellos abierto hace un cuarto de siglo en el Monasterio de San Martín de Castañeda, y el otro desde 2010 en un edificio de nueva planta construido junto a la localidad de Rabanillo. Ambos, como si una mala conciencia los moviera a ello, cuentan en su exposición permanente dedicada a los valores ecológicos y naturales con una suerte de "sección etnográfica" o al menos llamada a exhibir elementos de la cultura tradicional de la zona, se supone que conservada de una forma en alguna medida pareja a la naturaleza que la aísla y ensalza. Hasta ahí, una sabia decisión. Sin embargo, en ambos casos sucede lo mismo: los aperos y enseres recabados en estas tierras se ofrecen como una especie de batiburrillo sin conexión con el resto, en ámbitos aparte, sin integración ni conexiones: son meros depósitos de objetos que algún día fueron algo más. El mismo planteamiento, la misma estrategia, idéntico resultado. Eso sí: ha cambiado la forma, el lenguaje expositivo. Donde antaño había meros poyetes y etiquetas de papel, hogaño se hace gala de diseño, tecnología y lo que se viene en llamar a la anglosajona, el packaging. No sabría decir cuál resulta menos pertinente.

22. A pesar de los esfuerzos demostrados en Alonso, Díaz y Piñel, 2008 con encomiable voluntad de cambiar las cosas. 


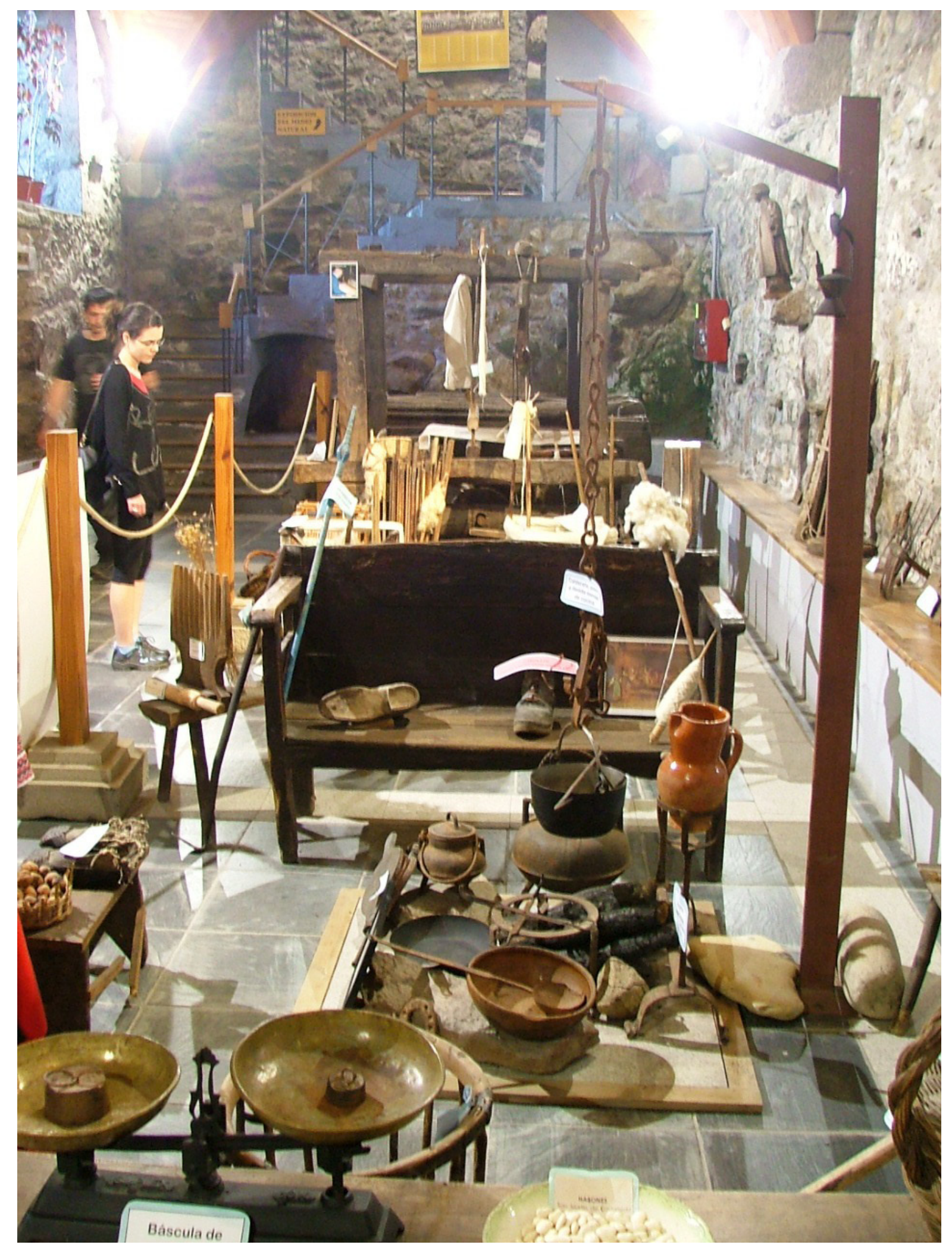

Foto 3: Sección etnográfica del centro de interpretación del Parque natural del lago de Sanabria en el monasterio de San Martín de Castañeda (Zamora) 


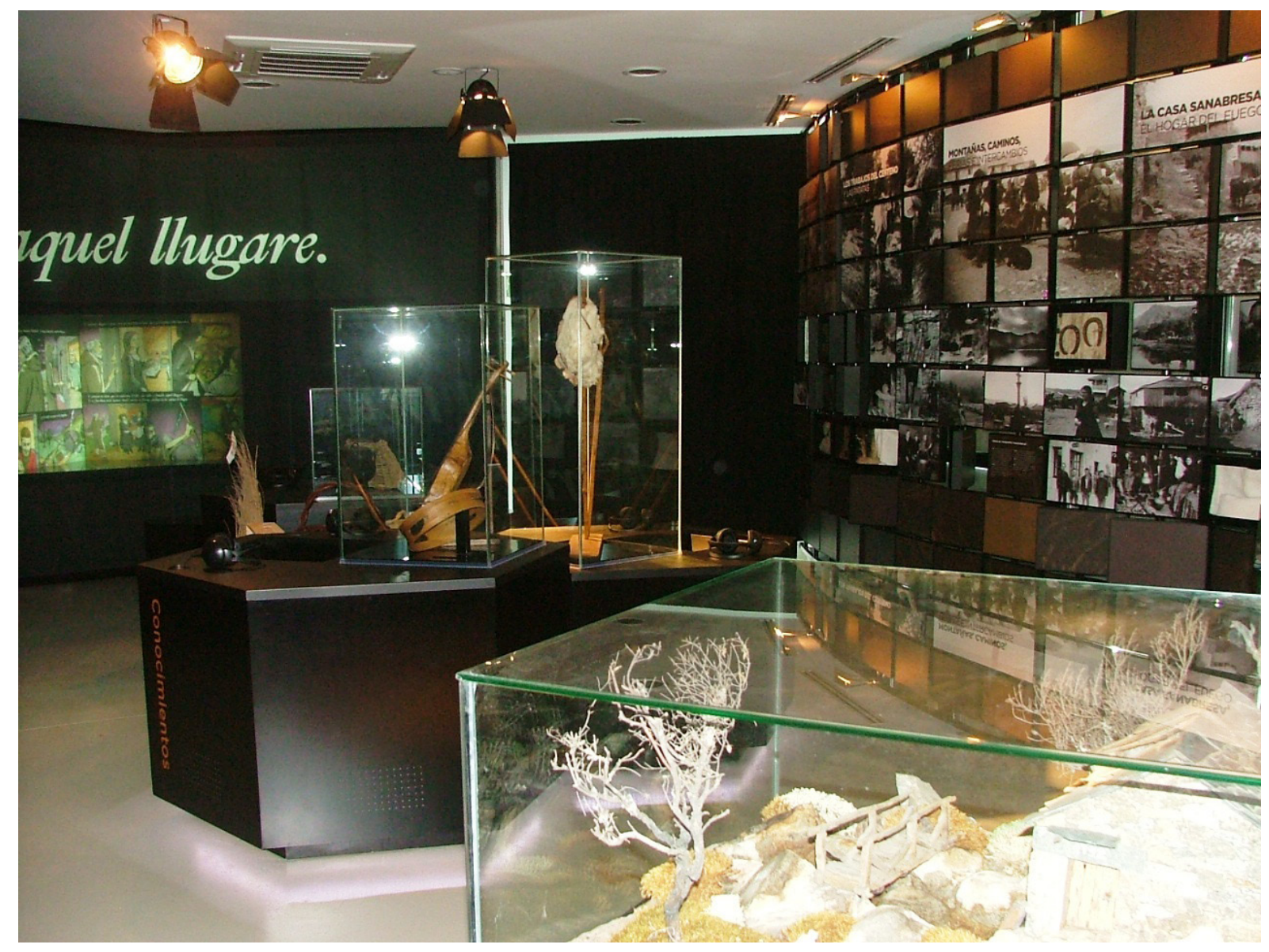

Foto 4: Sección etnográfica del centro de interpretación del Parque natural del lago de Sanabria en Rabanillo (Zamora)

\section{CODA SOBRE LA ANTROPOLOGÍA EN LOS MUSEOS. SEÑORA DE ROJO SOBRE FONDO GRIS}

Si bien se mira, un museo siempre resulta contradictorio. Cualquier museo. Los de arqueología porque la esencia de esa disciplina contradice el afán de permanencia del museo. Los de bellas artes porque congelan la emoción e impiden supuestos y stendhalianos síndromes. Los de arte contemporáneo porque nada hay más incoherente que meter el presente en un museo. Y así, ad infinitum: el museo, esa criatura paradójica. Pero también criatura necesaria, porque desde que el mundo fue interrogado, el museo ha sido la forma escogida por sociedades e individuos para interpretarlo, para elaborar un pequeño mapa a escala, una baedeker compuesta de pequeños objetos destinados a mostrarlo y demostrarlo, a acomodarlo a nuestra forma de ver las cosas. El museo, así visto, deviene una creación eminentemente antropológica, el destilado último de una perspectiva única e irrepetible. Sabemos más de nosotros por lo que decimos y callamos 
en ellos, pese a que sean museos dedicados a otros, que por cualquier otra expresión menos elaborada o colectiva.

Quizás por ello, los museos antropológicos, los etnológicos, aquellos dedicados al estudio de lo que hace del ser humano en sociedad un espécimen de interés en sus muy diversas formas de afrontar la realidad, convoquen un porcentaje de contradicción aún más elevado. Y es que la antropología, definida en alguna parte como astronomía de las ciencias sociales, proporciona un gran angular en que caben todas y cada una de las posibilidades de análisis del individuo y sus agrupaciones. Pero, al mismo tiempo, suele centrarse en aspectos relacionados con una forma de pretérito imperfecto, un pasado no cumplido del todo, aún no exánime, que sigue actuando de una u otra manera en el tejido social y en el sentimiento personal. De ahí que frecuentemente convoque la nostalgia o el agridulce regusto de los recuerdos. Y de ahí también que a veces uno visite los museos etnológicos y piense que los objetos se exhiben allí como en una morgue (todo museo lo es, por supuesto), un depósito de cadáveres exquisitos a la espera de su funeral, un funeral que sucederá en otra estancia diferente, la que convertirá a tales reliquias en el testimonio de épocas definitivamente extintas, y hará de ellas las piezas de un museo arqueológico; o las dotará de aquellos elementos sublimes que apreciamos en las obras de arte, trasmutándolas en un museo de ese tipo. ¿Son, por tanto, los museos etnológicos la antesala o el embrión de otros museos? ¿De ahí su renuncia y/o renuencia a una postura más crítica? ¿Pueden verse como una exposición temporal, con fecha de caducidad, cuya transubstanciación o conversión en permanente dependerá de una nueva y ajena formulación, y de un futuro que preludian pero al que son incapaces de servir? Quizás. Pero se me antoja que también esos son, a la postre, argumentos que podrían trasladarse al resto de los museos, sean del tipo que fueren. Museos, esos santos inocentes.

Villamayor del Condado (León), abril de 2015. 


\section{REFERENCIAS BIBLIOGRÁFICAS}

Alonso, Joaquín y Grau, Luis (1995) "Museos etnográficos en Castilla y León: entre la realidad y el deseo". Anales del Museo Nacional de Antropología II, pp. 119-127.

Alonso Ponga, José Luis, Díaz González, Joaquín y PIÑEL, Carlos, Dirs. (2008) Teoría y praxis de la museografía etnográfica. Actas del I Congreso internacional de museografía etnográfica. Zamora: Museo Etnográfico de Castilla y León.

Azuar, Rafael (2013) Museos, arqueología, democracia y crisis. Gijón: Trea.

Balboa, José Antonio (2006): El patrimonio industrial de la provincia de León. León: Instituto Leonés de Cultura y Diputación de León.

Bolaños, María (1997): Historia de los museos en España. Gijón: Trea.

Calvo, Luis (1986): "Etnografía y folklore en Castilla”. En A. Aguirre (ed.) La antropología cultural en España. Barcelona: PPU.

Casado, Concha (1995): El Alfar-Museo de Jiménez de Jamuz. León: Diputación provincial. Celis, Jesús (2009): “Museo etnográfico provincial, Mansilla de las Mulas, León”, IV Encuentro Actualidad en Museografía. Madrid: ICOM 2008.

Díaz, Luis (1986) Etnología y folklore en Castilla y León. Valladolid: Junta de Castilla y León. Fernández, Jorge Juan (2003) Museos y colecciones de Castilla y León. Valladolid: Ámbito.

Gamoneda, Antonio, Coord. (2006) Museo Sierra-Pambley, Guía. León: Fundación Sierra-Pambley.

García Castellón, Fernando (1997) Los molinos y fábricas de harina en Castilla y León. Valladolid: Junta de Castilla y León.

Grau, Luis (1998) "Un museo de provincias y una provincia de Museos, el caso de León". En V Coloquio galego de Museos de 1997. Melide (A Coruña): Consello Galego de Museos, pp. 263-275.

Grau, Luis (2007) "Modelos de organización museística: sobre redes y sistemas”, MUS-A 8: Museos locales: naturaleza y perspectivas, pp. 57-65.

Grau, Luis (2009) “Museos en León y el Museo de León como referencia al servicio de un territorio". En Iñaki Arrieta Urtizberea (ed.) Activaciones patrimoniales a iniciativas museísticas ¿por quién? y ¿Para quién? Bilbao: Universidad del País Vasco, pp. 151-172.

Ponga, Juan Carlos y Rodríguez, Araceli (2000) Arquitectura popular en las comarcas de Castilla y León. Valladolid: Junta de Castilla y León.

Ruiz, Juan José (1991) Etnografía soriana. Museos etnográficos rurales. Soria: Diputación provincial. 
Veleda, Manuel Jesús (2003) Museos Etnográficos Vallisoletanos. Valladolid: Diputación provincial.

VV.AA. (1993) Museos y colecciones de León. León: La Crónica de León.

VV.AA. (2004) Catálogo del Museo etnográfico de Castilla y León. Valladolid: Junta de Castilla y León.

VV.AA. (2005) Criterios para la elaboración del Plan Museológico. Madrid: Ministerio de Cultura.

VV.AA. (2001) Estudios de etnología en Castilla y León (1992-1999). Valladolid: Junta de Castilla y León. 